\title{
Ecologia na Formação do Profissional de Saúde: Promoção do Exercício da Cidadania e Reflexão Crítica Comprometida com a Existência
}

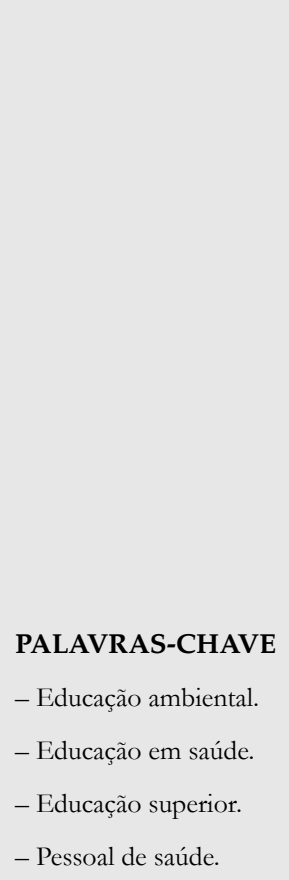

\section{KEYWORDS}

- Environmental education.

- Healthy education.

- Education highes.

- Health personnel.

Recebido em: 19/04/02

Aprovado em: 28/09/2008

\section{Ecology in Undergraduate Education in the Health Field: Promoting an Exercise in Citizenship and Critical Reflection Committed to Life}

\author{
Rodrigo Siqueira-Batista ${ }^{I}$ \\ Giselle Rôças ${ }^{I I}$ \\ Andréia Patrícia Gomes ${ }^{I I}$ \\ Verônica Santos Albuquerque ${ }^{I I}$ \\ Flávia Monteiro de Barros Araújo \\ Jorge Cardoso Messeder ${ }^{I I I}$
}

\section{RESUMO}

Este manuscrito, baseado em revisão de literatura, convida à reflexão sobre a importância da discussão das questões ecológicas na formação do profissional de saúde. Entre os aspectos considerados fundamentais, inclui-se a revisão da Agenda 21 e as interações entre os processos produtivos, o consumo, as inovações tecnológicas e a degradação da saúde e do meio ambiente. A proposta central desta discussão é a sensibilização para incorporar o debate sobre a relação entre ambiente e saúde nos currículos dos diversos cursos da área da saúde, incluindo graduação e pós-graduação. Considera-se que essas reflexões no espaço acadêmico são formas potenciais de promover a responsabilização dos futuros profissionais de saúde no exercício da cidadania, destacando o comprometimento presente e futuro com a existência e com as condições e a qualidade de vida dos indivíduos, da sociedade e do planeta.

\section{ABSTRACT}

Based on a literature review, this paper invites the reader to reflect on the importance of ecological issues as part of undergraduate training in health. Key aspects include a review of Agenda 21 and the interactions between industrial processes, consumption, technological innovations, and degradation of health and the environment. The central proposal in this discussion is sensitization to incorporate the debate on the relationship between the environment and health into the curriculum in various health courses at both the undergraduate and graduate levels. Such reflections in the academic sphere are potential ways to foster responsibility by future health professionals in their exercise of citizenship, highlighting current and future commitment to life and the living conditions and quality of life for individuals, society, and the planet. 


\section{INTRODUÇÃO}

A crise ambiental e suas repercussões na existência humana e de outros seres vivos são temáticas centrais em todos os espaços de reflexão na vida cotidiana. Especial destaque deve ser dado aos cenários educacionais, públicos ou privados, compreendendo todos os níveis de formação, da educação infantil à pós-graduação. Partindo desse pressuposto, os docentes envolvidos no ensino da área da saúde devem se tornar permeáveis às reflexões dirigidas à relação entre a ecologia e a saúde, além da discussão da necessidade de inclusão de um debate crítico, contínuo e mobilizador sobre as questões ambientais na formação dos profissionais de saúde ${ }^{1}$. De fato, Likic et al. ${ }^{2}$ concordam com a presente proposição quando inferem que a perspectiva de discutir os princípios ecológicos nos cursos de graduação é um dos elementos de maior relevância nos debates atuais sobre a formação dos profissionais da área de saúde.

A ecologia pode ser entendida, da perspectiva etimológica, como o estudo da casa - em grego óikos ${ }^{3}$. Do ponto de vista científico, todavia, essa caracterização se amplia, podendo a ecologia ser definida como o estudo da relação dos organismos ou grupos de organismos com seu meio ambiente - ou ainda, como a ciência das inter-relações entre organismos vivos e seu ambiente. Neste movimento, o ecossistema se estabelece como seu conceito-chave, ao se considerar que os constituintes da natureza não existem isolados uns dos outros e tendem a se combinar em sistemas complexos, estabelecidos a partir de uma série de relacionamentos físicos, químicos e biológicos ${ }^{4}$.

A abordagem ecológica, no presente ensaio, considera como ponto central a relação homem-natureza e parte de dois pressupostos apresentados por Minayo ${ }^{5}$ para o debate sobre saúde e ambiente: o primeiro é a essencialidade da relação entre os seres humanos e a natureza; o segundo, derivado dessa relação, é de que o conceito de ambiente é construído pela ação humana. Dessa forma, ele é histórico e pode ser pensado, repensado, criado e recriado, tendo em vista a responsabilidade presente e futura com a existência, as condições e a qualidade de vida dos indivíduos, da sociedade e de toda a biosfera.

Reconhecendo-se que (1) os desdobramentos da atual questão ambiental se entrelaçam com os demais aspectos das crises social, econômica, política e tecnológica enfrentados na contemporaneidade e que (2) há marcante influência das relações homem-natureza nos processo saúde-doença da espécie humana - aspecto reconhecido, no Ocidente, desde Hipócrates de Cós ${ }^{6}-$, o escopo do presente manuscrito é discutir a inclusão da ecologia nos currículos dos cursos das ciências da saúde.

\section{MÉTODOS}

Trata-se de uma pesquisa teórica apoiada na revisão crítica da literatura. Os textos foram buscados nas bases BVS (Biblioteca Virtual em Saúde), Pubmed (U. S. National Library of Medicine) e Scielo (Scientific Eletronic Library Online), bem como nos livros e nos capítulos de livro das áreas de ecologia e de saúde ambiental. A partir da leitura dos manuscritos obtidos foi possível construir uma síntese reflexiva sobre o tema.

\section{RESULTADOS E DISCUSSÃO}

Por ocasião do nascimento da ecologia, em $1869^{7}$, não foi possível antever o impacto que a questão ambiental envolveria nos 150 anos subsequentes, com profundos desdobramentos em distintos campos do saber. De fato, nas últimas décadas, a ecologia tem se tornado um dos saberes com maior possibilidade de contribuição para os debates sociais, éticos, políticos e econômicos nas sociedades contemporâneas, em decorrência dos díspares problemas ambientais que acometem o planeta Terra, entre eles o buraco na camada de ozônio, o aquecimento global, as mudanças climáticas e o agravamento das catástrofes naturais. Em escalas variáveis, tais alterações do ambiente provocam distúrbios em diversas regiões e possibilitam a ocorrência de inúmeras condições mórbidas, como as enfermidades infecciosas, os acidentes relacionados ao calor e ao frio excessivos, e os efeitos deletérios da maior exposição à luz solar, elementos com grande impacto sobre a saúde dos indivíduos e das populações ${ }^{8,9}$.

Acredita-se que a tônica dessa discussão esteja na relação entre a sociedade de consumo e os impactos ambientais consequentes à atividade econômica, contemplando reflexões abrangentes e específicas sobre o ambiente no campo da saúde; ou seja, o apelo ao consumo de bens e serviços e a estratégia de ligar esse consumo ao desfrute, ao prazer, ao bem-estar e à felicidade são algumas das características da sociedade contemporânea. Como algo inerente ao homem, o consumo se vincula ao próprio desenvolvimento civilizatório ${ }^{10}$. Entretanto, essa necessidade desenfreada de consumo vem exaurindo não somente os recursos ambientais, mas também a saúde humana, uma vez que a qualidade de vida tem sido posta em patamar secundário, em busca de ganhos financeiros capazes de manter esse padrão de vida.

A discussão do "consumismo" e da crise ambiental deve ser obrigatória em todo projeto político-pedagógico que valorize a cidadania na constituição do perfil profissional. É importante contextualizar essa crise no cerne da sociedade de consumo, construída sob a lógica mercadológica do capitalismo. Tomando por base as propostas de Freitas et $\mathrm{al}^{11}$, as reflexões devem incluir: 1) o crescente nível de degradação do ambiente 
e dos riscos ecológicos globais que afetam a vida do planeta; 2) a previsão de escassez de recursos naturais básicos para a produção e o consumo, como uma crítica ao pensamento liberal, pautado na ideia de abundância e infinitude dos bens; e 3) a pressão social para controle dos riscos industriais.

Existem outros dois conceitos importantes a serem trabalhados na formação em saúde: a dominação antropocêntrica da natureza e o desenvolvimento sustentável. Minayo 5 infere que, na atualidade, a palavra "desenvolvimento" parece inspirar mais problemas do que soluções, num mundo que globaliza, além dos processos de produção, de consumo e de bens culturais, fomes continentais, poluição, desemprego estrutural, violências, drogas, esgotamento das matérias-primas, ameaça de extinção de espécies e desastres ecológicos. Como um contraponto a esses problemas, a sustentabilidade incorporada nos discursos e nas práticas precisa substituir o padrão de desenvolvimento predatório, predominante no século XX.

Ao discutir os sintomas da crise civilizacional, Boff ${ }^{12}$ (p. 20) ressalta a falta de cuidado com o meio ambiente:

Há um descuido e um descaso na salvaguarda da nossa casa comum, o planeta Terra. Solos são envenenados, ares são contaminados, águas são poluídas, florestas são dizimadas, espécies de seres vivos são exterminadas; um manto de injustiça e de violência pesa sobre dois terços da humanidade. Um princípio de autodestruição está em ação, capaz de liquidar o sutil equilíbrio físico-químico e ecológico do planeta e devastar a biosfera, pondo em risco a continuidade do experimento da espécie homo sapiens e demens.

Na enorme crise ecológica que afeta o planeta, Mann ${ }^{13}$ considera o efeito estufa e a redução da camada de ozônio como as ameaças mais sérias, cujos variados impactos afetam a biodiversidade, a sustentabilidade e até a sobrevivência de cidades.

Diante do contexto apresentado, a formação de profissionais de saúde precisa reavivar e aprofundar o debate sobre o pensar e o agir frente à temática ambiental, observando avanços e retrocessos. Muitos são os aspectos a considerar, como a revisão da Agenda 21, debates sobre risco no campo da saúde e no campo ambiental, além das interações entre os processos produtivos, o consumo, as inovações tecnológicas e a degradação da saúde e do ambiente ${ }^{14}$.

Considera-se que debates sobre a Agenda 21 - termo usado para designar o plano de ação para o desenvolvimento sustentável, proposto no relatório da Unced (United Nations Commission on Environment and Development), a partir da
Rio-92 - devem ser promovidos no espaço acadêmico como forma de sensibilizar e responsabilizar os futuros profissionais de saúde no exercício da cidadania. A Agenda 21 teve como signatários 178 chefes de Estado e de governo e configurou-se como um pacto internacional a partir de recomendações que objetivaram criar um processo para a substituição negociada do padrão de desenvolvimento predatório, predominante no século XX. Nela foi estabelecida, claramente, a estreita relação entre saúde e ambiente. Um capítulo inteiro da Agenda 21 está dedicado à proteção e à promoção da saúde humana ${ }^{15}$.

As interações entre os processos produtivos, o consumo, as inovações tecnológicas e a degradação da saúde e do ambiente também são questões fundamentais para o aprofundamento teórico e reflexivo na formação em saúde. Nesse sentido, o foco propositivo da discussão centra-se no modo de produção e consumo da sociedade capitalista. Deve considerar o surgimento do capitalismo - e, particularmente, a Revolução Industrial - como momento de introdução de profundas rupturas nas relações, apresentadas por Rigotto ${ }^{16}$ : o "trabalho" é convertido em "emprego" e passa a ser progressivamente organizado em um complexo sistema de produção que instaura relações profundamente novas entre os produtores, os meios de produção e os consumidores. Concentrando capital, força de trabalho, técnica, máquinas e matérias-primas, a indústria destrói ou redefine o meio rural, produz ou amplia aglomerações urbanas, estabelece novos modos de relacionamento sociedade-natureza, dando à intervenção humana escala e intensidade até então desconhecidas ${ }^{17}$. A produção passa a responder às necessidades do mercado e a ser orientada pelo lucro. Mudam o caráter da pressão sobre o ambiente físico e a concepção de tempo: o horizonte temporal não é mais orientado pelos ciclos da natureza, mas sim pela amortização dos investimentos. A tecnologia torna-se um fator exógeno à cultura individual e social, e privilégio de um pequeno grupo de países, organizações e empresas ${ }^{18}$.

Conhecer e analisar as crenças, valores e atitudes gestados a partir do surgimento do modo de produção e consumo capitalista é essencial para formar profissionais críticos e reflexivos, capazes de compreender as relações entre esse modo de produção e os problemas ambientais e de saúde que a humanidade hoje enfrenta. Nesse contexto, é importante que a formação se preocupe com algumas temáticas levantadas por Rigotto ${ }^{16}$, promovendo uma discussão sobre a separação entre ser humano e ambiente, a possibilidade de explorar sem limites os recursos do planeta, a capacidade da Terra de receber nossos dejetos, o domínio da natureza e a exploração dos seres humanos por intermédio da ciência e da técnica, o consumismo como ethos e os "países desenvolvidos" como modelo para os demais. 
Deve, igualmente, ser ressaltada a potencialidade do desenvolvimento do pensamento crítico, considerando as questões ambientais, na produção do conhecimento em saúde. Para Minayo ${ }^{15}$, urge o trabalho com uma metodologia cuja base filosófica seja comunicativa, aberta, inclusiva e de responsabilização de todos. Assim, tanto as pesquisas como as ações práticas devem contemplar os vários atores responsáveis pela relação com o ambiente, numa forma de atuação que os cientistas da área vêm chamando de "ciência pós-normal" ou "comunidade ampliada de práticas" para se referirem às diferentes categorias de sujeitos que devem ser incluídos. $\mathrm{O}$ processo de construção do desenvolvimento sustentável supera qualquer visão unidisciplinar e estática das relações do ser humano com a natureza. Em concordância com a visão apresentada, Constanza ${ }^{19}$ ressalta a necessidade de reintegrar o estudo dos seres humanos e do restante da natureza em abordagens transdisciplinares e multiescalas, em conjunto com um consistente desenvolvimento de uma teoria da coevolução cultural e biológica. Essa reintegração e esse aprimoramento teórico contribuiriam para construir um mundo mais sustentável e desejável, que reconhece a premência de uma parceria fundamental com a natureza.

\section{CONSIDERAÇÕES FINAIS}

A ecologia "transbordou" os limites da Biologia ${ }^{20}$, transitando do campo estrito das ciências naturais para o campo social e da saúde. De fato, a ecologia convida a pensar as relações entre os diferentes seres que compõem o planeta, colocando em questão o lugar ocupado pela espécie Homo sapiens sapiens na natureza ${ }^{21}$.

Deve se estimular a inserção da discussão dos conceitos ecológicos na formação do profissional da saúde tanto com a inclusão de uma disciplina sobre ecologia - no caso dos currículos de estrutura disciplinar-, como por meio da transversalidade do tema ambiente e saúde, permitindo criar um vínculo mais claro e objetivo, como preconizado pelas ações de saúde ambiental e pelos Parâmetros Curriculares Nacionais (PCN). Embora estes últimos, os PCN, sejam orientados somente para a Educação Básica, não há motivos para o impedimento da aplicação dessa abordagem interdisciplinar no ensino superior. Dessa forma, a atuação durante o processo de formação desses novos profissionais ocorrerá de maneira mais integrada e atualizada, permitindo que eles possam perceber a aplicação contextualizada dos conteúdos teóricos da área de saúde no ambiente "real".

Como brevemente pontuado, essa perspectiva tem se mostrado com evidente impacto sobre a saúde, não cabendo ao aparelho formador se esquivar destes debates. Seguindo tal proposição, deve-se procurar discutir, paulatinamente, o impacto ecológico nas ações cotidianas - enquanto profissionais de saúde, mas, sobretudo, enquanto cidadãos, contexto extremamente salutar para a formação acadêmica -, num movimento capaz de tornar as pessoas mais conscientes de si e mais responsáveis com o ambiente, permitindo que a Terra permaneça habitável e sustentável para as gerações presentes e futuras.

\section{REFERÊNCIAS}

1. Philippi Júnior A. Saneamento, saúde e ambiente: fundamentos para um desenvolvimento sustentável. São Paulo: Manole; 2004.

2. Likic R, Dusek T, Horvat D. Analysis and prospects for curricular reform of medical schools in Southeast Europe. Med Edu 2005; 39(8):833-840.

3. Rôças G, Siqueira-Batista R, Gomes AP, Araújo F, Messeder JC, Cotta RMM. Ecologia e saúde: debates atuais na educação médica In: 45o Congresso Brasileiro de Educação Médica, 2007, Uberlândia. Rev Bras Educ Med 2007; 31:749-750.

4. Ricklefs RE. A economia da natureza. 5 ed. Rio de Janeiro: Guanabara Koogan; 2003.

5. Minayo MCS. Saúde e ambiente no processo de desenvolvimento. Cienc saude colet. 1998; 3(2):4-5.

6. Hippocrates. Airs Waters Places. With an english translation by W. H. S. Jones. Cambridge, Harvard University Press; 1992.

7. Haeckel E. Natürliche Schöpfungs-geschichte. 2 ed. Berlin: Georg Reimer; 1870.

8. Freitas CM. Problemas ambientais, saúde coletiva e ciências sociais. Cienc saude colet. 2003; 8(1):137-150.

9. Capra F. Alfabetização ecológica. São Paulo: Cultrix; 2006.

10. Nascimento AC. "Ao persistirem os sintomas, o médico deverá ser consultado". Isto é regulação? São Paulo: Sobravime; 2005.

11. Freitas CM, Soares M, Porto MFS. Subsídios para um programa na Fiocruz sobre saúde e ambiente no processo de desenvolvimento. Rio de Janeiro: Fiocruz; 1999.

12. Boff L. Saber cuidar. Ética do humano: compaixão pela terra. Petrópolis: Vozes; 1999.

13. Mann E. Dispatches from Durban. California: Frontline Press; 2002.

14. Albuquerque VS, Giffin KM. Globalização capitalista e seus impactos na vida cotidiana: Uma agenda necessária à formação superior em saúde. Trab. Educ saúde. No prelo 2008.

15. Minayo MCS. Saúde e ambiente: uma relação necessária. In: Campos GWS, Minayo MCS, Akerman M, Drumond 
Jr. M, Carvalho YM. Tratado de saúde coletiva. São Paulo: Hucitec; Rio de Janeiro: Fiocruz; 2006. p. 93-122.

16. Rigotto R. Produção e consumo, saúde e ambiente: em busca de fontes e caminhos. In: Minayo MCS, Miranda AC. Saúde e ambiente sustentável: estreitando nós. Rio de Janeiro: Fiocruz; 2002. p. 233-260.

17. Costa WM. Bases epidemiológicas da questão ambiental. In: IBAMA. Seminário Universidade e Meio Ambiente. Documentos Básicos. Brasília: IBAMA; 1990.

18. Herrera AO. Meio ambiente, tecnologia e empobrecimento global. In: IBAMA. Seminário Universidade e Meio Ambiente. Documentos Básicos. Brasília: IBAMA; 1990.

19. Constanza R. A vision of the future of science: reintegrating the study of humans and the rest of nature. Futures 2003; 35: 651-671.

20. Boff L. Ética da vida. Rio de Janeiro: Sextante; 2005.

21. Rôças G, Siqueira-Batista R, Gomes AP, Castro JSM. Bioética e ecologia: interseções de saberes e comportamentos. Anais do VII Congresso Brasileiro de Bioética. São Paulo; 2007.

\section{CONTRIBUIÇÃO DOS AUTORES}

Rodrigo Siqueira-Batista, Giselle Rôças e Andréia Patrícia Gomes conceberam a estrutura do artigo e elaboraram a primeira versão; Verônica S. Albuquerque revisou o manuscrito e colaborou, especialmente, na redação da seção "Resultados e Discussão"; Flávia M.B. Araújo e Jorge Cardoso Messeder realizaram a leitura crítica do texto com contribuições decisivas para a seção "Considerações finais".

\section{CONFLITO DE INTERESSES}

Declarou não haver

\section{ENDEREÇO DE CORRESPONDÊNCIA}

Instituto Federal de Educação, Ciência e Tecnologia do Rio de Janeiro.

Rua Lucio Tavares, 1045

Centro - Nilópolis

CEP.: 26530-060 - RJ

E-mail: rsiqueirabatista@terra.com.br 